\title{
Applications of Glass Fibers in 3D Preform Composites
}

\author{
Kadir Bilisik, Gaye Kaya, Huseyin Ozdemir, \\ Mahmut Korkmaz and Gulhan Erdogan \\ Additional information is available at the end of the chapter
}

http://dx.doi.org/10.5772/intechopen.73293

\begin{abstract}
E-glass three dimensional (3D) stitched preform composites have been developed for several industrial applications due to their high mechanical performance and damage tolerance properties. Although some in-plane properties of the stitched E-glass composite structure are slightly lower than in laminated composite, its mode-I delamination failure is improved. This was achieved by using the out-of-plane directional stitched fibers. Recently, some nanoparticles as single-walled nanotubes (SWNT) or multiwalled nanotubes (MWNT) or nanofibers (NF) were added to the glass fabric structure or stitched preform during consolidation process. This further enhances the thermo-mechanical impact properties of the E-glass fiber composites.
\end{abstract}

Keywords: glass fiber, nanosilicate, nanocarbon, preform, 3D fabric architecture

\section{Introduction}

Textile fiber composites have been used in various space-aerospace, ballistic, industrial, and medical areas due to their high stiffness to weight ratio and damage tolerance properties [1]. The most important reasons for the increased use of textile structural composites are the increased expectations for product performance and demand for lightweight materials in global markets.

Textile-based composites consist of fibers with high strength and modulus properties, and matrix materials that bond these fibers together to provide load transfer and structural integrity. Fibers provide strength and stiffness to the composite materials, while the resins basically keep the fibers together to transfer stresses between the fibers. Glass fibers are the most common of all reinforcing fibers for polymeric matrix composites, which have low cost, high tensile strength, high chemical resistance, and excellent insulating properties [1-3]. 
Glass fibers are used as other reinforcement fibers in manufacturing of textile preforms for composites. The textile preform fabrication is done by weaving, braiding, knitting, and stitching and by using nonwoven techniques, and they can be chosen generally based on the enduse requirements. Originally, three dimensional (3D) preforms can be classified according to fiber interlacement types. Simple 3D preform consists of two dimensional (2D) fabrics and is stitched depending on stack sequence. More sophisticated 3D preforms are fabricated by specially designed automated loom and manufactured to near-net shape to reduce scrap [4-6].

In polymeric materials, the use of organic and inorganic fillers has become very common. Polymer composites are used commercially in various areas such as construction and civil engineering, automobile components, and sports equipment. Over the past 20 years, great importance has been attached to the development of polymeric nanocomposites. In nanocomposites where at least one of the components is in the nanometer range, the final product is in micro- or macrosize. In addition, advances in computer technology have facilitated the characterization of nanomaterials and their estimation through modeling and simulations [7].

This chapter deals with applications of glass fibers in 3D preform composites. The fabrication, classification, and properties of glass fibers were introduced. Types of matrix and properties of used nanofillers in textile-based polymeric composites in the form of sphere, tubes, and fibers were explained. 2D and 3D fabric forms of glass fibers were reviewed especially considering the 3D stitched composite. Basic fabrication methods of composites were provided. Mechanical properties and failure modes of glass fiber-reinforced 3D composites were discussed by considering the special application areas.

\section{Glass fibers, matrix, and nanoadditives}

\subsection{Glass fibers}

Glass can be finely spun into fibers that are pliable to be woven into textiles. Glassy materials, above their glass transition temperature, $\mathrm{T}_{g^{\prime}}$ show Newtonian viscosity, i.e., the stress is proportional to the strain rate. This property is exploited in the drawing of glass into fiber and planar forms [8]. Glass fibers are used in manufacturing structural composites, printed circuit boards, and a wide range of special-purpose products [9]. Glass fiber manufacturing is the high-temperature conversion of various raw materials, which are predominantly borosilicate, into a homogeneous melt, followed by the fabrication of this melt into glass fibers [10]. The most important melt properties of fiberglass melts are the fiber-forming viscosity, the temperature at which fibers are formed, and the liquid temperature at which crystals can form within hours and remain in equilibrium with the melt [11]. The basic component of glass fibers is silica (silicon dioxide $\left(\mathrm{SiO}_{2}\right)$ ) derived from ordinary sand, and the viscous melts can be strong melts typically containing $50-100 \% \mathrm{SiO}_{2}$ and $0-25 \% \mathrm{Al}_{2} \mathrm{O}_{3}[12,13]$. The continuous fibers are produced using bushings, which have a few hundred to several thousand small tubes of the bushing. One fiber is produced from each tip. The temperature of the glass exiting tip is typically in the range of $1150-1300^{\circ} \mathrm{C}$, depending upon the composition of the glass. 
The glass will normally flow out of the bushing under the force of gravity into fibers on the order of $1 \mathrm{~mm}$ diameter. The final diameter of the glass fiber is a strong function of the tension applied to the fiber as it is being drawn [14]. Figure 1 shows the manufacturing of glass fibers and some produced glass fiber tows $[15,16]$.

The compositions of the glass fibers vary depending on glass types (A-glass, S-glass, or E-glass). More than $99 \%$ of continuous glass fibers are spun from an E-glass [17]. The remaining glass fibers are premium special-purpose products [18]. Table 1 presents the glass fiber types with short explanations [19].

The physical properties of glass fibers are affected by the compositions. The two types of glass fibers commonly used in the fiber-reinforced plastic industry are E-glass and S-glass [2]. Therefore, the physical properties of these fibers are generally discussed. The densities of E-glass and S2-glass fibers are $2.58 \mathrm{~g} / \mathrm{cm}^{3}$ and $2.46 \mathrm{~g} / \mathrm{cm}^{3}$, respectively. The softening points of E-glass and S2-glass are $846^{\circ} \mathrm{C}$ and $1056^{\circ} \mathrm{C}$, respectively. The tensile strengths and modulus are $3345 \mathrm{MPa}$ and $72.3 \mathrm{GPa}$ for E-glass and $4890 \mathrm{MPa}$ and $86.9 \mathrm{GPa}$ for S2-glass, while the elongations are 4.8 and $5.7 \%$, respectively [19]. Scanning electron microscope (SEM) views of E-glass fiber and tow are shown in Figure 2 [20].

\subsection{Matrix}

Polymer-based matrix materials are basically classified into two main groups as thermoset and thermoplastic. In general, thermoset polymeric resins have a widespread use in fiber-reinforced composites. The fibers are applied with these resins using the resin transfer molding or recently vacuum-assisted resin transfer molding techniques. During processing, the viscosity of the polymer is low during the interaction of the fiber with the matrix.

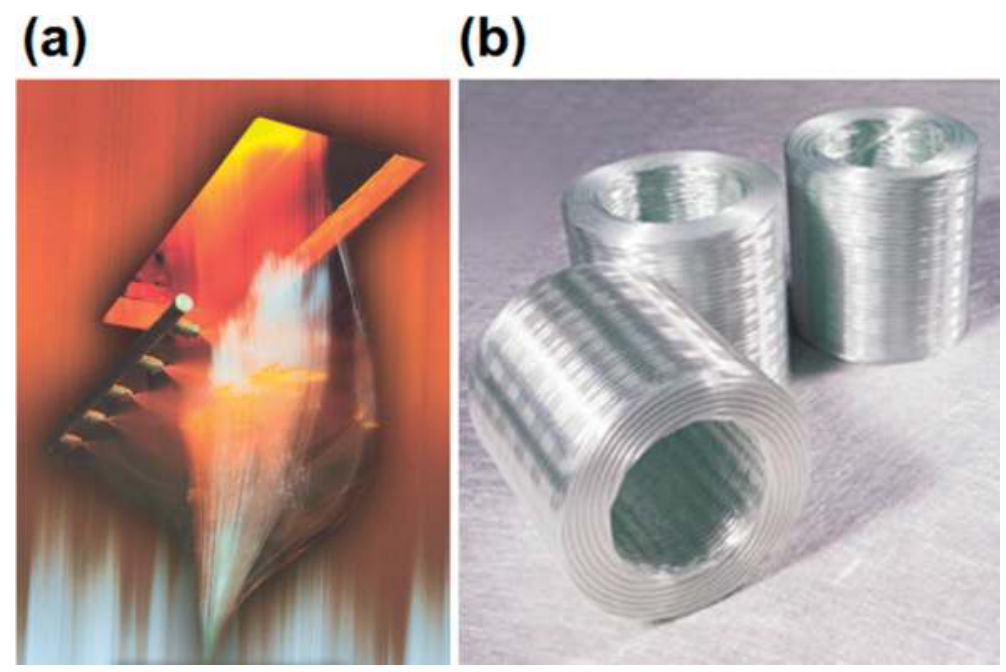

Figure 1. (a) Drawing of glass filaments and (b) glass tows $[15,16]$. 


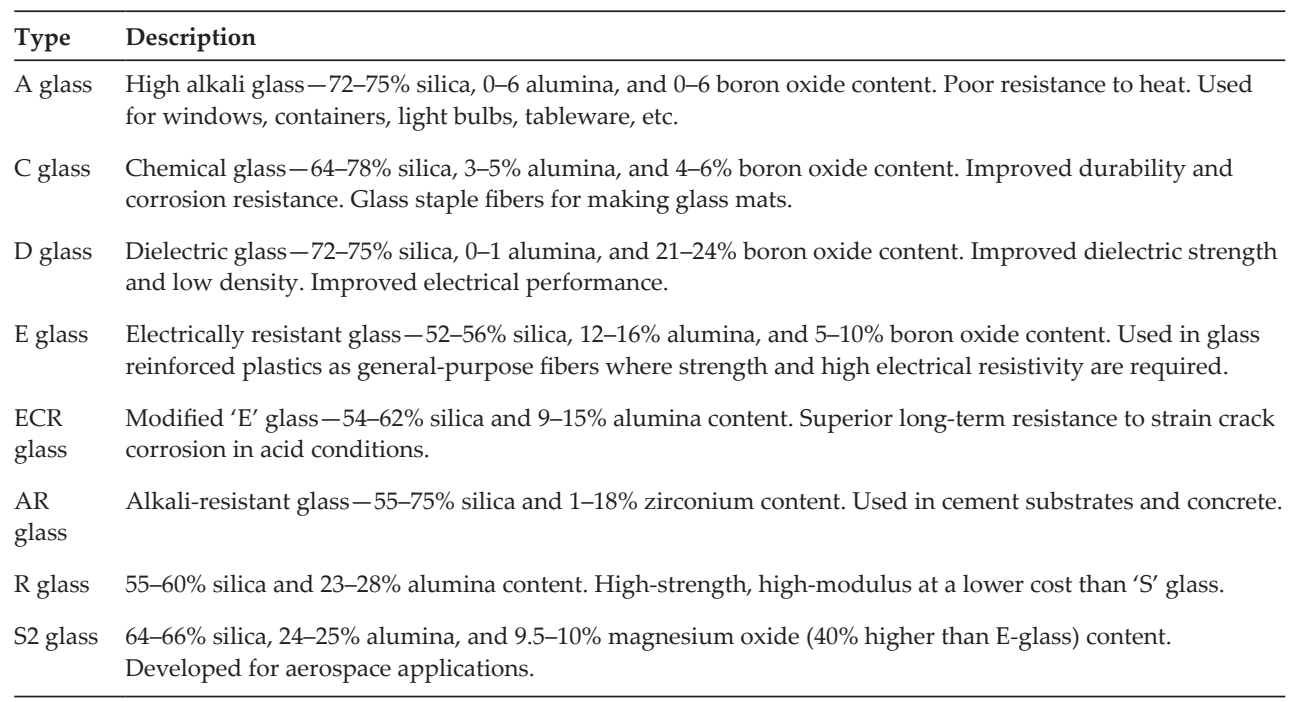

Table 1. Glass fiber types and some of their physical and chemical specifications [19].

(a)

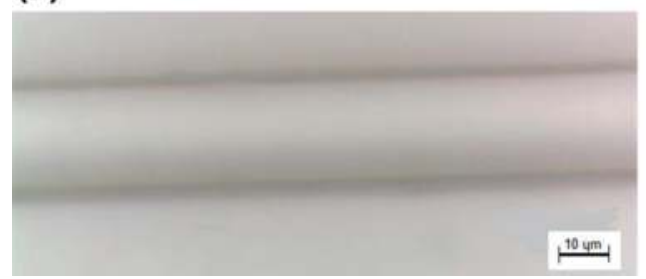

(b)

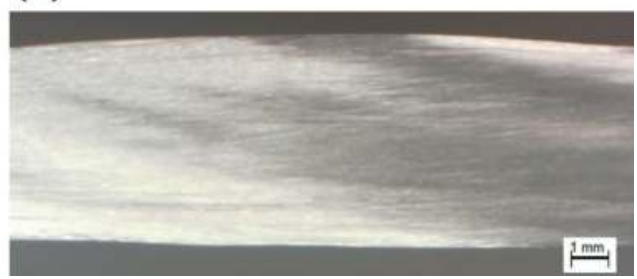

Figure 2. SEM views of E-glass fiber and tow. (a) E-glass fiber and (b) E-glass tow [20].

This provides good wetting properties between the fiber and the matrix without any additional high temperature or pressure. However, the low strain properties of thermoset resins reduce the impact strength of the composites. The most widely used thermoset resins are epoxy, polyester, phenolic, and vinyl ester $[1,2,21]$.

There is a growing interest in development and production of the thermoplastic polymerbased composites. The reason of this interest is the ability of thermoplastic composites to form and remold easily in shorter process times compared to thermoset composites. Furthermore, thermoplastic composites provide high fracture toughness, damage tolerance, and microcrack resistance $[22,23]$. Thermoplastic resins are about 500-1000 times more viscous than thermoset resins. This restricts the infusion tendency of resins to fibers. In addition, the need for high pressures in thermoplastic composite process is also considered as another limiting factor. Semicrystalline thermoplastic polymers such as polyether ether ketone (PEEK), polyphenylene sulfide (PPS), and liquid-crystal polymers (LCP) are mainly used in aviation due to their 
mechanical and chemical resistance at relatively high temperatures. Some other thermoplastic polymers such as polypropylene(PP), acrylonitrile butadiene styrene (ABS), and polyamide (PA) find use in the automotive industry. PP has a very common use in the production of thermoplastic composites due to its low cost, high specific properties, and reusability [24, 25]. The properties of some of the thermoset and thermoplastic resins are presented in Table 2 [21].

Polyesters are used extensively in continuous and discontinuous composites and they are relatively inexpensive with processing flexibility. They are cured by addition reactions in which unsaturated carbon-carbon double bonds $(\mathrm{C}=\mathrm{C})$ are the locations where cross-linking occurs. Typical polyester consists of at least three ingredients: a polyester, a cross-linking agent such as styrene, and an initiator, usually a peroxide, such as methyl ethyl ketone peroxide (MEKP). One of the main advantages of polyesters is that they can be formulated to cure at either room temperature or elevated temperatures, allowing great versatility in their processing. Epoxies are high-performance matrix systems for primarily continuous fiber composites and have better high-temperature performance than polyesters and vinyl esters. Epoxies are used in resin transfer molding, filament winding, pultrusion, hand layup, and other processes with various high-modulus and high-strength fibers. The properties of the resultant resins are strongly dependent on the cross-linking [2,3]. Vinyl esters are similar to polyesters but are tougher and have better moisture resistance [2, 26].

\subsection{Nanoadditives}

Nanoparticles have been identified in the last decade as an important class of materials for various emerging applications in optics, electronics, or the biomedical area. Many of the potential applications are based on two major changes when the scale of material structures decreased. These are the high surface-to-volume ratio and the improvement of the electronic properties [27]. Nanocomposites can be described as particle-filled polymers in which at least one of the components is in nanometer dimensions [28]. The investigation of fullerenes (nanosphere) and carbon nanotubes (CNT) has opened a totally new window for the development of polymer matrix composites with novel properties and applications [29]. Nanofillers have a considerable potential in improving the properties of polymeric composites [30, 31]. The stiffness, toughness, and abrasion resistance of nanocomposites depend on the size, shape, ratio, and uniform distribution of the fillers in the polymers [32]. It can be possible to obtain

\begin{tabular}{lllll}
\hline Polymer & Resin & Density $\left(\mathrm{g} / \mathrm{cm}^{3}\right)$ & Tensile modulus $(\mathrm{GPa})$ & Tensile strength $(\mathrm{MPa})$ \\
\hline Thermoset & Epoxy & $1.2-1.4$ & $2.5-5.0$ & $50-110$ \\
& Phenolic & $1.2-1.4$ & $2.7-4.1$ & $35-60$ \\
& Polyester & $1.1-1.4$ & $1.6-4.1$ & $35-95$ \\
Thermoplastic & Polyamide & 1.1 & $1.3-3.5$ & $55-90$ \\
& PEEK & $1.3-1.35$ & $3.5-4.4$ & 100 \\
& PPS & $1.3-1.4$ & 3.4 & 80 \\
\hline
\end{tabular}

Table 2. The specification of thermoset and thermoplastic matrix [21]. 
materials with high toughness values by producing nanocomposites with high nanoparticle ratio, homogeneous alignment, and high interface strength [33]. Interfacial bond properties between nanoparticle and matrix in the composite are active research subject in the research and development societies [31]. Nanosphere, single-walled, or multiwalled tubes were applied to the composites by dispersing the nanoparticles in the resin using various techniques such as shear mixing, ultrasonication, calendering, ball milling or ultrasonication-extrusion, and transfer-printing. If nanofibers were used, they were attached, grown, or grafted onto fibers or 2D fabrics. Full deagglomeration of CNTs using mixers is difficult to achieve. High flow rates creating high-shear forces cause well distribution of agglomerated CNTs. However, their breakage is not avoided and the presence of CNT agglomerates is usually observed [34]. Various nanosized materials were developed by employing the up-to-date processing as silica is one of the most important and most studied oxide nanoparticle types. Due to its quite simple preparation, its chemical inertness, and the relatively inexpensive precursors, it became a prominent compound in academics and in commercial applications [27]. Because of its high specific component of surface energy, silica has a stronger tendency to agglomerate than carbon black [35]. Figure 3 shows the SEM (scanning electron microscope) micrograph of nanosilica and nano- and microcarbon spheres [20].

In the past few years, novel materials such as carbon nanotubes (CNTs) and related technologies have posed a strong candidacy for providing an integrated approach toward enhanced structural integrity and multifunctionality [36]. The development of novel glass fiber-reinforced plastics (GFRPs) with electrical conductivity has opened up new opportunities for damage sensing. Adding a small amount of carbon nanotubes to form an electrically conductive network is a promising approach to monitor damage initiation and propagation for glass fiber-reinforced composites [37].

The pre-dispersed overcoating of nanotubes and the process modifications allow improvement of the interface properties of $2 \mathrm{D}$ woven E-glass composites since the reinforcement effect of nanotubes on z-direction [38]. The amine functionalized carbon nanotubes had improved tensile strength compared to neat [39]. The modulus of composites is enhanced by the addition of silicon carbide nanoparticles by considering dispersion of these particles in resin, which highly depends on the coupling agents and dispersants [40]. Moreover, the weak

(a)

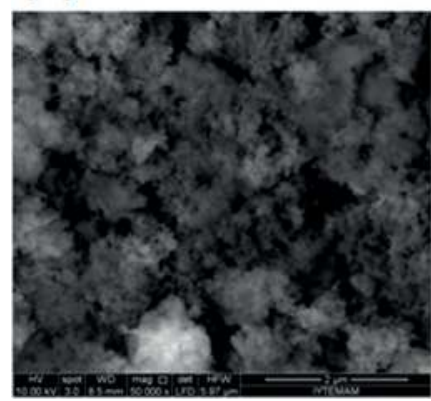

(b)

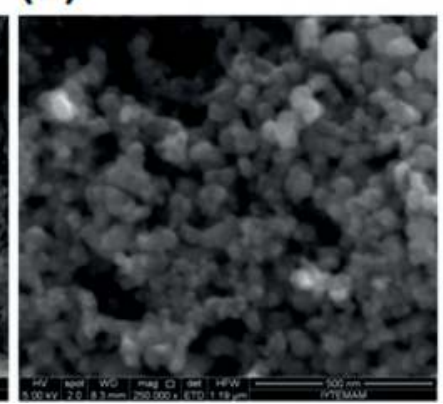

(c)

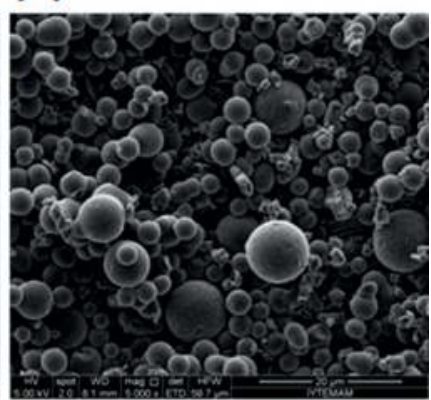

Figure 3. SEM micrograph of some nanofillers. (a) Nanosilica (magnification 50,000×); (b) nanocarbon (magnification 250,000×); and (c) nanocarbon (magnification 5000×) [20]. 
bonds at the interfaces of silicon carbide nanoparticles and resin lead to stress concentration rely on the particle geometry [41].

\section{2D fabrics and 3D preforms}

\subsection{Two dimensional (2D) fabrics}

The most preferred 2D fabrics in textile structural composites are discussed as 2D woven fabric, triaxial woven fabric, braided fabric and knitted fabric, uniaxial and biaxial knitted fabrics, and nonwoven fabric. The most common fabric used in the textile structural composites is $2 \mathrm{D}$ woven fabric due to its more stable property compared to the knitted fabric. To form the $2 \mathrm{D}$ woven fabric, there are two yarn sets as warp and weft interlace each other at right angle. 2D woven fabric has three types of main patterns as plain, twill, and satin and also a lot of derivative patterns. Because the plain woven fabric is formed by more interlacement points between warp and weft, its structural characteristics become more rigid, less flexible, and more durable. Twill woven fabric has inclined paths from right to left or from left to right on the fabric surface due to its interlacements of warp and weft. In satin woven fabric, warp has long floats, which are evenly distributed through the fabric. It has low crimp ratio. The schematic views of weaves and microscopic view of E-glass plain woven fabrics are shown in Figure 4 [20].

The schematic views of triaxial woven fabric and braided fabric are shown in Figure 5(a) and (b). As shown in Figure 5(a), triaxial weave has three sets of yarn as +bias, -bias, and weft yarn in which these yarns take in interlacements [42]. This fabric has large gaps in the crossing region of warp and weft due to interlacements and it restricts to make dense fabrics during 2D woven fabric formation [44]. 2D braided fabric has one yarn set as braiders, which have $+\theta^{\circ}$ and $-\theta^{\circ}$ orientations. As shown in Figure 5(b), these braider yarns are intertwined with each other to make the 2D braided fabric structure [43].

Figure 6(a-g) shows the schematic views of weft and warp knitted fabrics and uniaxial and biaxial knitted fabrics. The knitted fabric is constituted from yarn loops connected to each other and to the neighboring rows and columns by various techniques. The basic knitting types are weft knitting (Figure 6a) and warp knitting (Figure 6b) [45].

(a)

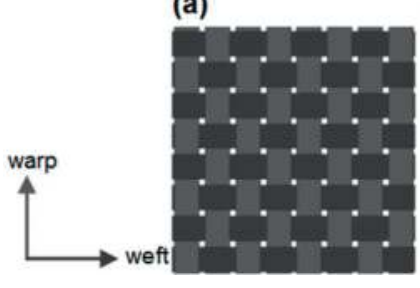

(b)

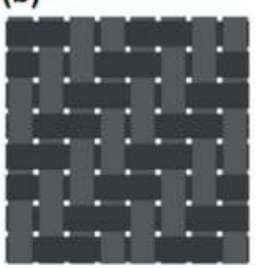

(c)

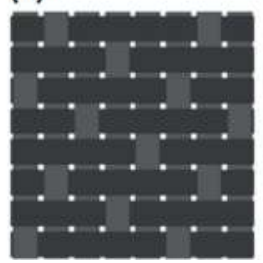




\section{(a)}

(b)

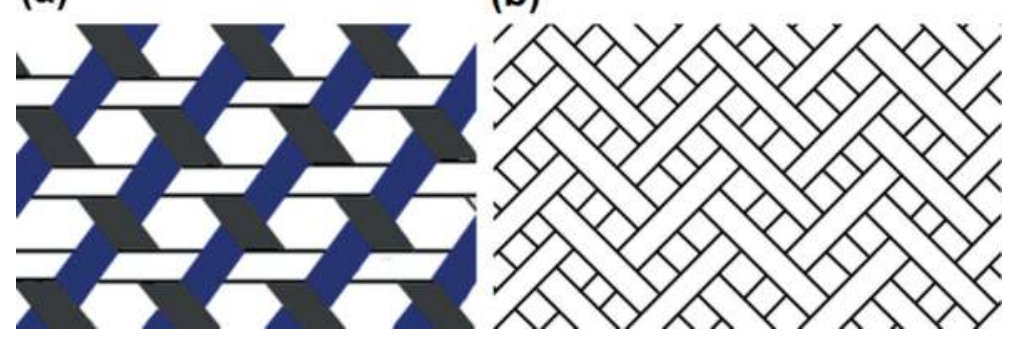

Figure 5. Schematic views of triaxial woven and braided fabrics. (a) Triaxial woven fabric and (b) braided fabric [42, 43].

(a)

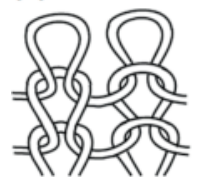

(b)

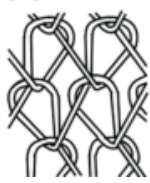

(c)

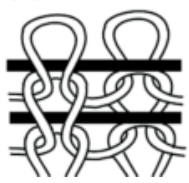

(d)

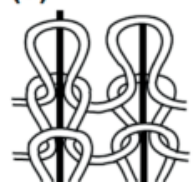

(e)

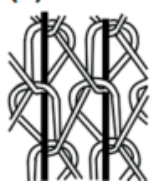

(f)

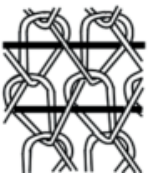

(g)

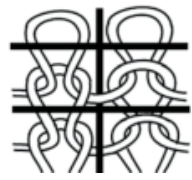

Figure 6. (a) Weft knitted fabric; (b) warp knitted fabric; (c) weft inlaid weft knitted fabric; (d) warp inlaid weft knitted fabric; (e) warp inlaid warp knitted fabric; (f) weft inlaid warp knitted fabric; and (g) $0^{\circ} / 90^{\circ}$ inlaid weft knitted fabric [45-47].

The uniaxial knitted fabric is a special type looped knitted fabric. It has big gaps, which lead to low fiber-volume-fractions, high-elongation, and low stiffness. Because of these restrictions, some structural modifications were performed by adding inlay yarns either in fabric length (Figure 6(d) and (e)) or width (Figure 6(c) and (f)). The tensile strengths of uniaxial knitted fabric composites improved in the direction of inlaid [46].

Biaxial knitted fabric is manufactured by introducing the warp $\left(0^{\circ}\right)$, weft $\left(90^{\circ}\right)$, or diagonal $\left( \pm 45^{\circ}\right)$ yarns into the weft (Figure 6 (g)) or warp knitted fabrics, which resulted as the improved mechanical properties of composites at the inlaid directions [48]. Nonwoven fabric is a web structure made up of short fibers that are held together by various techniques [49]. Nonwoven manufacture is that it is generally done in one continuous process directly from the raw material to the finished fabric [50]. Figure 7 shows the view of nonwoven glass mat [51].

\subsection{Three dimensional (3D) fabrics}

2D fabric-reinforced composites are a biaxially oriented planar structure. However, unidirectional fiber composite is an axially oriented planar structure. Both suffer from a delamination. 3D fabric preforms have been developed to make the delamination free composite.

Stitching can be used to make 3D fabrics using the 2D woven fabric [52]. 3D stitched fabric is manufactured by stitching $2 \mathrm{D}$ fabric layers in thickness direction. It can be stitched at one direction $\left(0^{\circ}\right)$, two directions $\left(0^{\circ}\right.$ and $\left.90^{\circ}\right)$, and four directions $\left(0^{\circ}, 90^{\circ}\right.$, and \pm bias $)$ as shown in Figures 8 and $\mathbf{9}$. Stitching can be made by sewing machine. The lock stitching is generally used in stitched preform fabrication for composites [53, 54]. 


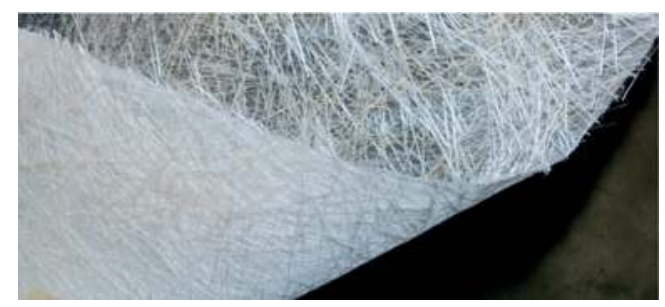

Figure 7. Nonwoven glass mat [51].

(a)

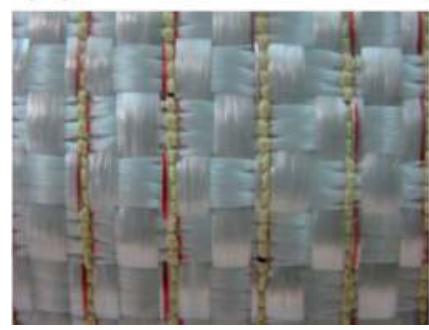

(b)

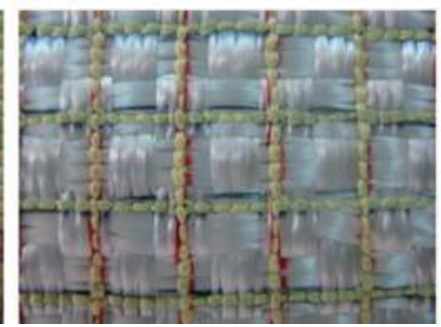

(c)

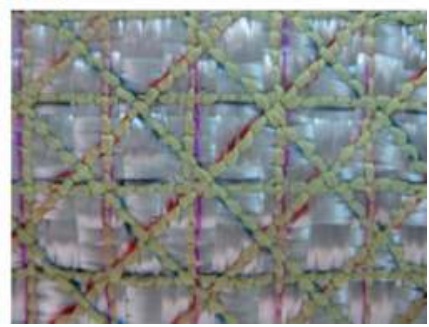

Figure 8. Top views of stitched E-glass preforms. (a) One-directional machine stitched; (b) two-directional machine stitched; and (c) four-directional machine stitched [53].

(a)

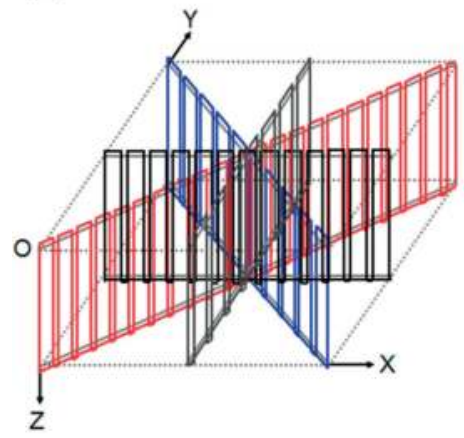

(b)

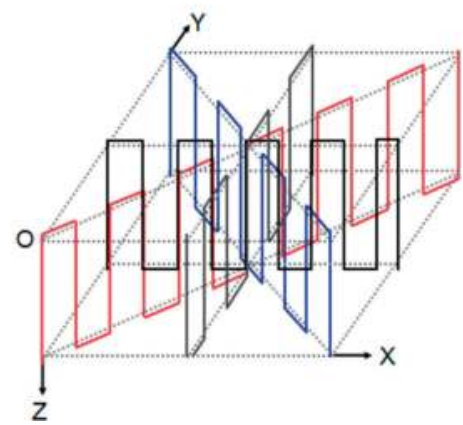

Figure 9. Schematic view of multistitched yarn paths. (a) Machine multistitched yarn path and (b) hand multistitched yarn path [54].

3D orthogonal woven fabric has three yarn sets as warp, weft, and z-yarn (Figure 10(a)). These yarn sets are interlaced to one another and oriented in three orthogonal directions to form the fabric [59]. Warp yarns are placed in the direction of the fabric length, while the weft yarns are inserted between the warp layers to form double picks. Z-yarns lock the other two yarn sets and provide structural integrity [48]. Figure 10(a-d) shows some of the 3D fabrics [55-58]. 
(a)

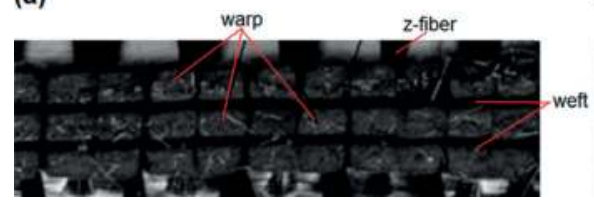

(b)

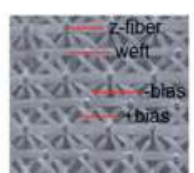

(c)

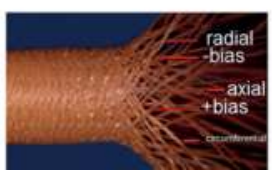

(d)

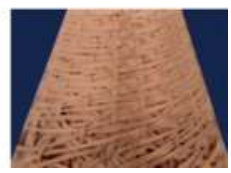

Figure 10. Some of the 3D fabrics. (a) 3D woven carbon fabric [55]; (b) multiaxis 3D woven carbon fabric [56]; (c) multiaxis 3D circular woven aramid fabric [57]; and (d) multiaxis 3D braided conical aramid fabric [58].

A multiaxis 3D woven fabric, method, and machine were developed by Mohamed and Bilisik [60]. The multiaxis 3D woven fabric has five yarn sets as +bias, -bias, warp, weft, and z-yarn. \pm Bias yarns are placed on the front face and back face. These yarns are locked to the other yarn sets by the z-yarns (Figure 10(b)). Multiaxis 3D circular woven fabric, method, and machine were developed by Bilisik. The 3D circular woven fabric has axial and radial yarns along with circumferential and \pm bias yarns (Figure 10(c)). Cylindrical preform can be made with thin and thick wall sections depending upon end-use requirements [61]. In multiaxis 3D braided fabric, braider yarns are intertwined with the axial yarns, whereas \pm bias yarns are oriented at the surface of the structure and locked by the radial yarns to the other yarn sets (Figure 10(d)). The properties of the multiaxial 3D braided structure in the transverse direction can be enhanced and the nonuniformity in the directional Poisson's ratios can be decreased [58, 62].

\section{Composite}

Several methods are developed in order to make composite based on 2D fabric and 3D preforms. The fiber properties, type of fabric formation and matrix, end-use requirement, and shape/size characteristics of the part influence the composite fabrication processes. Figure 11 shows the schematic views of some of the composite fabrication techniques [20,63].

Hand layup is the most commonly used composite fabrication method. It is still preferred because of highly flexible in design and suitable for the production of a wide variety of raw materials. The fabric layers are laid according to the desired thickness, and after each layer is laid, the resin is added by brush to spread the resin to wet the fibers. Then, the part is usually cured at room temperature and removed from the mold (Figure 11(a)). Resin transfer mold (RTM) is a recently introduced composite fabrication method to produce near-net shape parts.

(a)

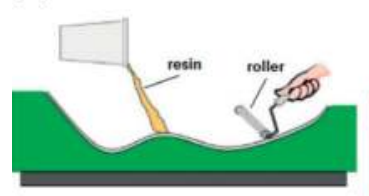

(b)

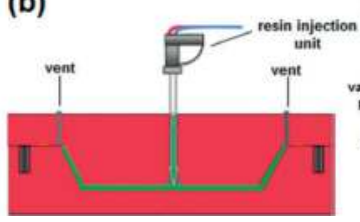

(c)

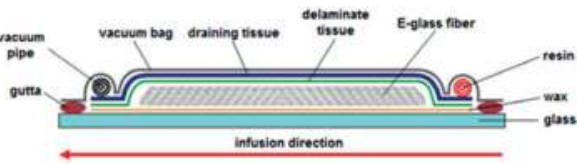

Figure 11. Schematic views of some of the composite fabrication techniques. (a) Hand layup; (b) resin transfer molding [63]; and (c) vacuum-assisted resin transfer molding [20]. 
The preform is placed in the gap between the molds. Then, the mold is closed and the gaps in the preform are filled by wetting all the fibers with resin. This process usually takes place under high pressure. The part is removed from the molds after curing (Figure 11(b)). The vacuumassisted resin transfer molding (VARTM) method is more cost-effective since it does not require a metallic mold. The preform is placed on the mold and covered with sealing tape with flexible vacuum film. The resin passes through the structure under vacuum and it is possible to produce high performance composite structures with high fiber volume fractions (Figure 11(c)) [1-3].

\section{Properties of preforms and composites}

3D glass woven preforms improve the out-of-plane properties of the composites. 3D stitched woven preforms also enhance the out-of-plane properties without decreasing the in-plane properties of the composite [64]. It is pointed out that the fracture mechanism of the stitched composite plates is affected by the loading direction in tensile test, but the stiffness of the structure is not significantly affected by the stitching [65]. The tensile strengths of stitched composite, in which twisted stitching yarns are utilized, is lower compared to the stitched composite having with untwisted stitching yarns [66]. It is demonstrated that stitching prevents the crack propagation [66,67]. The stitching causes local irregularities and undulation in the preform, which leads to a nonuniform fiber volume fractions and reduces the in-plane properties of the composite [68, 69]. In unstitched composites, delamination-based cracks are observed as a form of layer separation. However, in stitched composites, modeI failure is improved and catastrophic delamination is eliminated in which the composite becomes damage tolerance material. It is stated that the tensile strength of stitched composites is dependent on the parameters as stitching yarn type and stitching density. The $\pm 45^{\circ}$ directional off-axis tensile strengths of the 2D unstitched woven E-glass/polyester composites are $84.1 \mathrm{MPa}$ and $75.4 \mathrm{MPa}$, while the $\pm 45^{\circ}$ directional off-axis tensile strengths of the 3D stitched woven E-glass/polyester composites vary from 86.5 to $70.0 \mathrm{MPa}$ and from 83.5 to $64.1 \mathrm{MPa}$. The tensile strengths of four directional densely stitched composite is almost 15 and $6 \%$ lower than those of the unstitched composites at +45 and -45 directions, respectively. The similar trend is obtained for the $\pm 45^{\circ}$ directional off-axis tensile modulus of composite structures. The $\pm 45^{\circ}$ directional off-axis tensile modulus of the $2 \mathrm{D}$ unstitched woven E-glass/polyester composites is $5.9 \mathrm{GPa}$ and $6.2 \mathrm{GPa}$, while the $\pm 45^{\circ}$ directional off-axis tensile modulus of the 3D stitched woven E-glass/polyester composites vary from 6.4 to $4.0 \mathrm{GPa}$ and from 6.3 to $3.7 \mathrm{GPa}$. The tensile modulus of four directional densely stitched composite is almost 32 and $40 \%$ lower than those of the unstitched composites at +45 and -45 directions, respectively. These results show that when the stitching direction and stitching density in structures increase, their off-axis tensile strengths and modulus decrease since the multistitching process causes more filament breakages [70]. The warp and weft directional specific tensile strengths of the unstitched composites are higher than those in the multistitched composites due to stitching that causes filament breakages during insertion of the z-yarn. The stitching yarn types, stitch directions, and the stitch density generally influence the in-plane tensile properties of the multistitched E-glass/polyester woven composites. The warp-weft directional tensile strengths of the 2D unstitched woven E-glass/polyester composites are 
$303 \mathrm{MPa}$ and $285 \mathrm{MPa}$, while the warp-weft directional tensile strengths of the 3D stitched woven E-glass/polyester composites vary from 353 to $229 \mathrm{MPa}$ and from 345 to $209 \mathrm{MPa}$. The tensile strength of four directional densely stitched composite is almost 25 and $27 \%$ lower than those of the unstitched composites at warp and weft directions, respectively. The warp-weft tensile modulus of four directional densely stitched composite is almost 35 and 35\% lower than those of the unstitched composites at warp and weft directions, respectively. However, the warp-weft damaged areas of four directional densely stitched composite after tensile failure are almost 70 and $82 \%$ lower than those of the unstitched composites at warp and weft directions, respectively. The warp and weft directional damaged areas of multistitched composites decrease when the stitching directions in the out-of-plane of the structure increased. Therefore, the stitching yarns lock the in-plane directional warp and weft yarns in the layered woven structure and confine the damage areas at narrow regions, which considers as damage tolerant materials [71]. Furthermore, the off-axis tensile modulus of the multistitched composites decreases with the increase of the stitching direction and stitching density [70].

The warp and weft direction specific bending strengths and modulus of the unstitched/ nanocomposites are higher than those of the stitched composites since the stitching perhaps causes filament breakages during needle piercing action. The warp-weft specific strengths of four directional densely stitched composite are almost 25 and 31\% lower than those of the unstitched composites at warp and weft directions, respectively. On the other hand, the warp and weft directional damaged areas of the unstitched composites are higher than multistitched and multistitched/nanocomposites. The addition of the nanosilica to the stitched structures increases the damage tolerance [72]. One of the critical property of the stitched composite is also through-the-thickness directional shearing. The short-beam strengths of hand-stitched composites in the warp and weft direction increase slightly as the stitching direction increased from two directions to four directions. In addition, the warp and weft directional short-beam strengths of machine-stitched structures with high-modulus stitching yarns $\left(\operatorname{Kevlar}^{\circledast} 129\right)$ are higher than those of the machine-stitched structures stitched with low-modulus stitching yarns (Nylon 6.6) [73]. The tensile and impact behaviors of stitched E-glass/polypropylene woven composites are studied. The stitching in the through-the-thickness direction increases impact damage tolerance especially at low temperatures. It is claimed that there is a relation between stitching fiber fracture work and energy absorption based on fiber volume fraction in stitched composites [74]. The mechanical properties such as the tensile and compression and compression-after-impact (CAI) strength of noncrimped fabric are not degraded by the stitching parameters, whereas the tensile and compression strength and the tensile fatigue behavior are reduced as a result of pronounced localized fiber undulations due to stitching [68]. Stitched layered composite has slightly higher compression and CAI strengths than the integrally woven composite [75]. In addition, it is found that the strength of overlap joint during preforming is improved by using high-density chain stitching [76]. The damage initiation force for 3D noninterlaced stitched composite is lower than for the 2D unstitched woven composite due to weak resin-rich regions around the stitch loops. Densely stitched composite with more stitched-induced matrix cracks upon impact loading is due to the presence of weak resin-rich pockets around the stitching yarns [77-80]. The noncrimp stitched carbon fabric composite shows a quasi-isotropic behavior, while 2D woven composite demonstrated an anisotropic behavior. Stitching in the noncrimp carbon fabric has only a minor effect on its strength properties. Damage sites are mainly observed in the resin-rich 

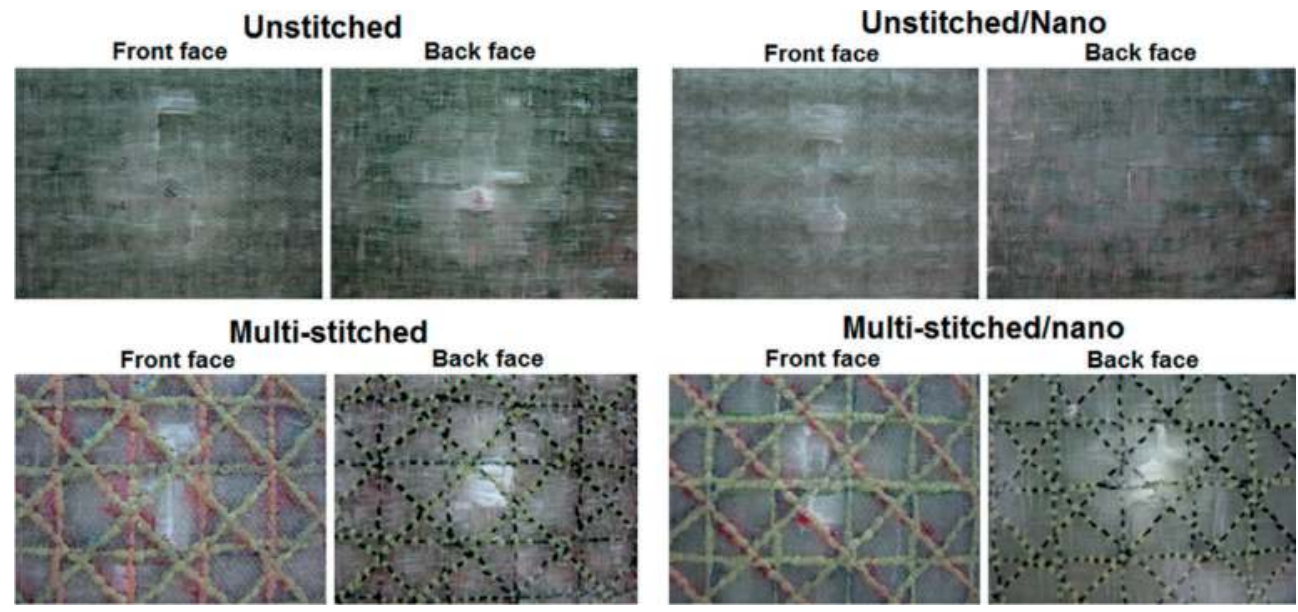

Figure 12. Damaged areas of composite after low-velocity impact test [82].

zones created by the stitching [81]. The low-velocity impact properties of the multistitched/ micro-/nano-E-glass/polyester woven composites are studied. It is observed that the material type (silicate or carbon or metal), the material particle size (nano or micro), amount of materials (weight, \%), stitching density (step/cm), and stitching type (hand or machine) influence the damaged areas of composites. Figure 12 shows the damaged areas of composite after lowvelocity impact test. The damaged areas of multistitched/nanosilica (5 wt.\%) composite after low-velocity impact test are almost 60 and $48 \%$ lower than those of the unstitched composites on front and back faces, respectively [82].

The multistitched and multistitched/nano-E-glass/polyester woven composite show a better damage resistance performance compared to those of the unstitched or unstitched/nanocomposites. The multistitching suppresses the impact energy relatively at a small area of the composite. In addition, adding the nanomaterial to the multistitched structure can further enhance the damage resistance performance [82].

\section{Glass fabric and glass composite applications}

The glass fiber-reinforced composites are used in a variety of forms to assure the required properties of usage areas as space, aerospace, automobile, energy, marine, electronic components, and defense-related special areas. The composites are designed according to service environments of usage areas in mechanical, impact, flammability, and electrical properties.

\subsection{Aviation and aerospace}

Although the volumes of fiber-reinforced polymer composites used for aircraft applications were a relatively small percentage, they found their most advanced applications in the fabrication of civil or military aircrafts [83]. For instance, the Boeing 787 made large use of composite materials in its airframe and primary structure. The use of composites, especially in the highly tension-loaded 
part of the fuselage, greatly reduced maintenance labor and cost. Figure $\mathbf{1 3}$ shows the percentages of used composite materials along with metals in commercial civilian airplane (Boeing 787) [84]. Typical glass fiber-reinforced composite applications in aircraft were engine cowlings, luggage racks, instrument enclosures, bulkheads, ducting, storage bins, and antenna enclosures. In addition, it was also widely used in ground-handling equipment [85].

\subsection{Automotive}

Glass fiber composite used in automotive is primarily driven by the demand for lightweight components, fuel efficiency, and recycling [86]. The two most common types of glass fibers used in automotive composites were the E-glass, which was cost-effective and had good tensile properties. Second one was S-glass, which had $40 \%$ higher tensile properties compared to the E-glass. But, it was expensive [87]. All glass fiber-based composites were used in automotive as primary or secondary structural parts of interior headliner, underbody system, and air intake manifold, instrument panel, bumper beam, and engine cover [88]. Figure 14 shows the glass fiber-based composite panels in car and trucks [63].

\subsection{Boats and marine}

Glass fiber both continuous TOW or discontinuous short forms has been the main material for the recreational boating industry, which was employed as hulls with a minimum number of assembled parts. Glass fiber-based composites have gained acceptance in pleasure craft because of light weight, vibration damping, corrosion resistance, impact resistance, low construction costs, and ease of fabrication, maintenance, and repair. Current leading-edge manufacturing technologies were driven by racing vessels, both power and sail $[85,89]$.

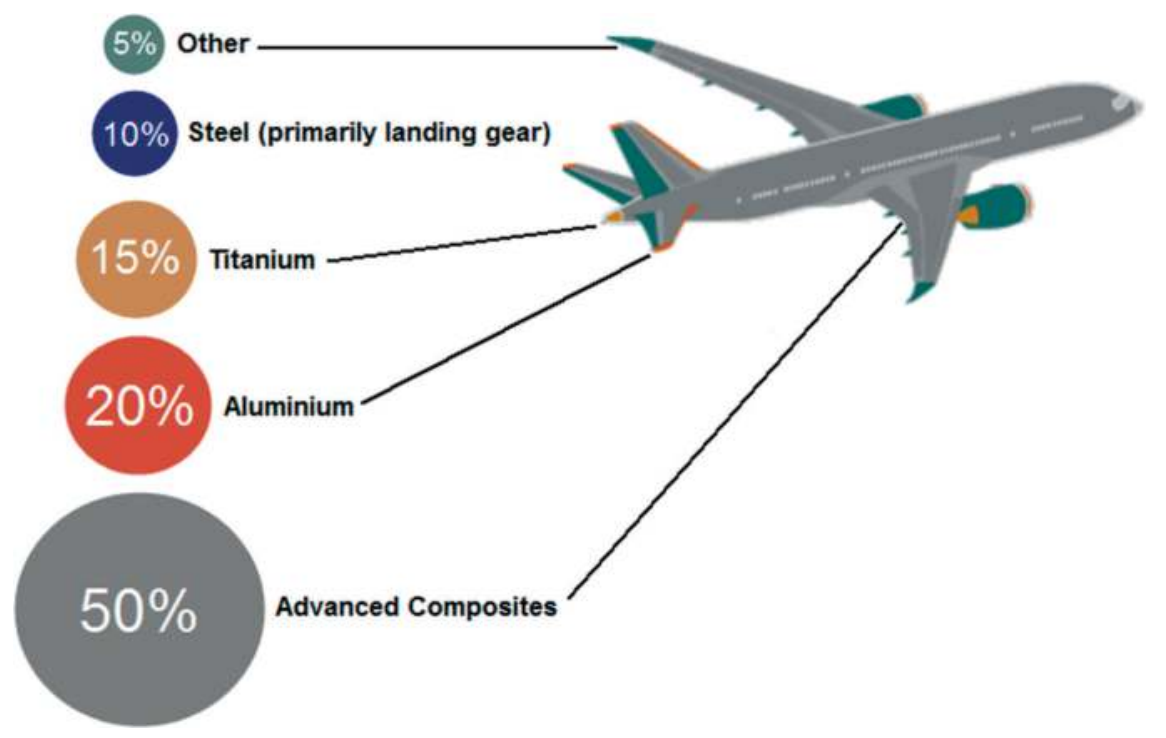

Figure 13. Composite materials used in civilian aircraft (Boeing 787) [84]. 

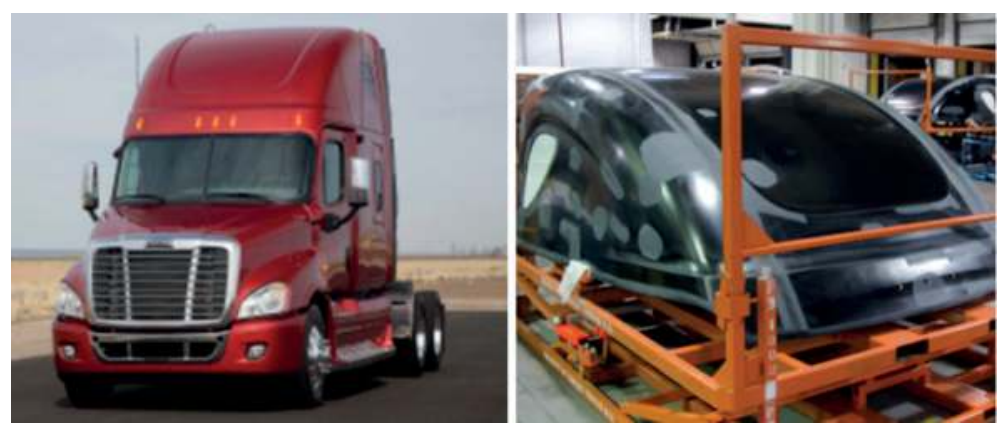

Figure 14. Glass fiber-reinforced composite body panels for truck and car [63].

\subsection{Electronics}

Glass fiber/epoxy composites have been the foundational structural substrate in printed circuit boards since 1980. They supported the transistors, resistors, and integrated circuits at all digital technologies. Glass composite board connected them electrically via conductive pathways etched or printed on their surfaces [90]. They were also used as insulators for high-voltage energy cabin components, a cable, or cable-coated material to transit the electrical energy [91].

\subsection{Wind energy}

In the sector of energy generation, glass fiber composites were utilized in manufacturing wind generators. The blades of the generators were generally made of epoxy resins reinforced with glass or carbon fibers. Their high mechanical strength and modulus made them attractive material for the wind blade in turbine generators [26]. Figure 15 shows the wind blades placed in the sea [92].

\subsection{Ballistic}

2D S2-glass fabric and 3D S2-glass preform composites were employed in ballistic armor. 3D S2-glass ballistic plate has better energy absorption properties due to z-yarn insertion in the through-the-thickness direction. This provided additional energy absorbing as a mechanism of high-strain interlayer deformations. In addition, 2D S2-glass fabric plate with or without

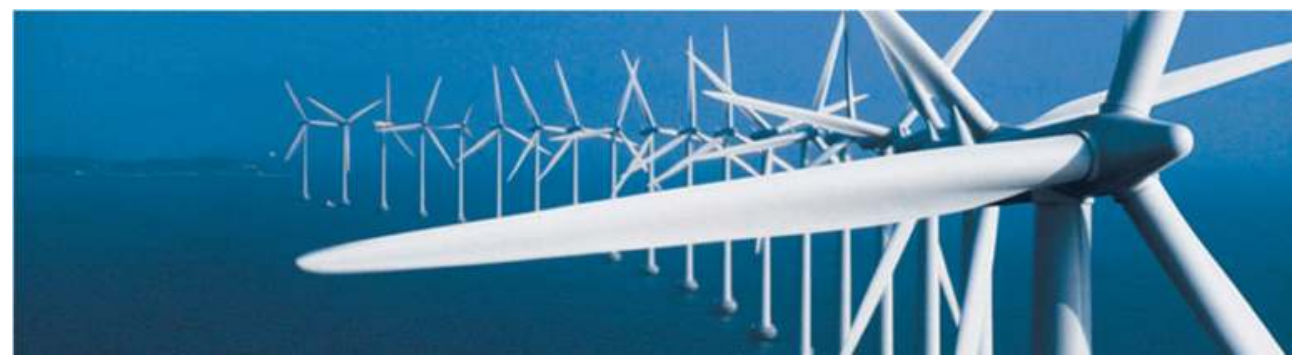

Figure 15. Wind blades placed in the sea [92]. 

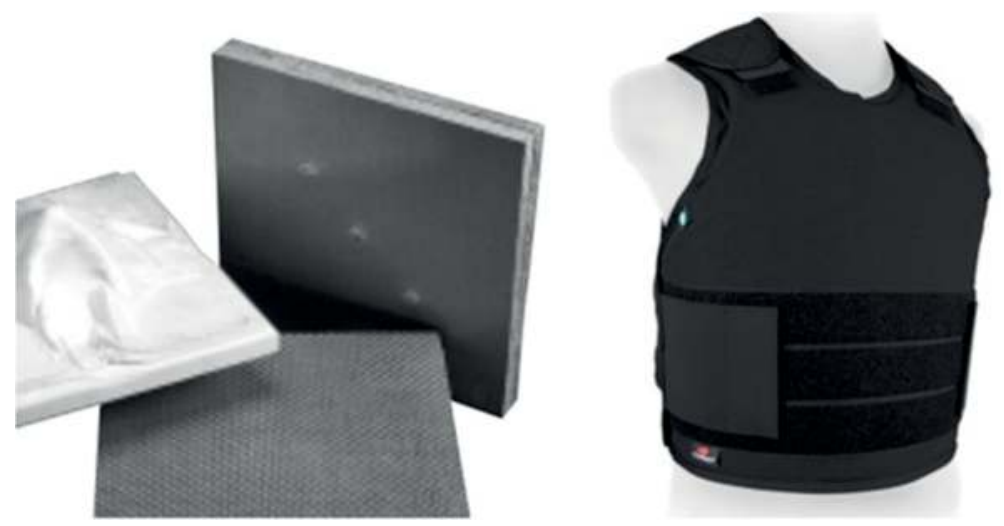

Figure 16. Glass fiber-based ballistic plate and bulletproof jacket [93].

stitching or 3D S2-glass preform composite plate has certain specific energy-absorbing advantages over the ceramic or metal armor plate. Figure 16 shows the glass fiber-based ballistic plate and bulletproof jacket $[26,93,94]$.

\section{Future trends}

Biaxial 2D woven fabrics have been widely used as simple and complex-shaped structural composite parts in various technical areas. In addition, biaxial weaving methods and techniques are well developed. 3D glass fabrics have multiple layers and show no delamination. 3D woven glass preform as well as multilayered stitched fabrics will be expanded in the field of especially marine and industrial applications as a form of composite structure. However, the multiaxis 3D weaving technique is at an early stage of development and needs to be fully automated. This will be a future technological challenge in the area of multiaxis 3D weaving.

\section{Conclusion}

In this chapter, two dimensional glass fabric (2D) and three dimensional (3D) glass preforms, fabrication methods, and application areas were reviewed. Glass fabrics were readily available and important, but they were specific segmented basic materials. 2D E-glass fabrics were traditionally employed in various industrial areas. 3D glass fabrics have multiple layers and no delamination due to out-of-plane directional fibers. Various techniques were also developed for 3D glass preforms. 3D orthogonal and stitched as well as multiaxis 3D knitted and 3D braided glass preforms are commercially available. On the other hand, various unit cell base models on 3D glass preform and composites were developed to define their geometrical and mechanical properties. Multiaxis 3D glass fabrics have multiple layers, and their in-plane properties are enhanced due to the bias yarn layers. However, the multiaxis 
3D woven preform technique is at an early stage of development. Recently, 3D woven and stitched glass preforms were made by adding single or multiwalled nanotubes and nanofibers to enhance their mechanical, thermal, and electrical properties. This will open up new material classes as well as application areas for near future.

\section{Sources of further information and advice}

Many studies have been carried out on the characterization and modeling of 2D and 3D glass preform composite structures, but limited information is available on the 3D fabric architecture and nanoadded glass fiber composites. Recent literature and books can be useful for having more information on these areas as indicated in Refs. [95-97].

\section{Author details}

Kadir Bilisik ${ }^{1 *}$, Gaye Kaya ${ }^{2}$, Huseyin Ozdemir ${ }^{3}$, Mahmut Korkmaz $^{4}$ and Gulhan Erdogan ${ }^{1}$

*Address all correspondence to: kadirbilisik@gmail.com

1 Department of Textile Engineering, Erciyes University, Turkey

2 Department of Textile Engineering, Kahramanmaras Sutcu Imam University, Turkey

3 Vocational School of Technical Sciences, Gaziantep University, Turkey

4 Mustafa Cikrikcioglu Vocational School of Technical Sciences, Erciyes University, Turkey

\section{References}

[1] Hoa SV. Principles of the Manufacturing of Composite Materials. Lancaster: DEStech Publications, Inc.; 2009. pp. 3-5

[2] Mallick PK. Fiber Reinforced Composites Materials, Manufacturing and Design. 2nd ed. Florida: CRC Press; 2007. pp. 60-116

[3] Campbell FC. Manufacturing Processes for Advanced Composites. Oxford: Elsevier; 2003. pp. 39-62

[4] Bilisik K. Multiaxis three dimensional (3D) woven fabric. In: Vassiliadis S, editor. Advances in Modern Woven Fabrics Technology. Zagreb, Croatia: InTech; 2011. pp. 80-106

[5] Brandt J, Drechsler K, Filsinger J. Advanced textile technologies for the cost effective manufacturing of high performance composites. RTO AVT Specialist Meeting on Low Cost Composite Structures; 7-11 May 2001; Loen, Norway

[6] Mohamed M. Three dimensional textiles. American Scientist. 1990;78:530-541 
[7] Hussain F, Hojjati M, Okamoto M, Gorga RE. Review article: Polymer-matrix nanocomposites, processing, manufacturing, and application: An overview. Journal of Composite Materials. 2006;40:1511-1575

[8] Chawla K. Fibrous Materials. Cambridge: Cambridge University Press; 2016. pp. 199-229

[9] Wallenberger FT. Melt viscosity and modulus of bulk glasses and fibers: Challenges for the next decade, in present state and future prospects of glass science and technology. In: Proceedings of the Norbert Kreidl Symposium; 3-8 July 1994; Liechtenstein; 1994. p. $63-78$

[10] Glass Fiber Manufacturing: United States Environmental Protection Agency (EPA) [Internet]. 2017. Available from: https://www3.epa.gov/ttnchie1/ap42/ch11/final/c11s13. pdf. [Accessed: 2017-06-10]

[11] Wallenberger FT. Commercial and experimental glass fibers. In: Wallenberger FT, Bingham PA editors. Fiberglass and Glass Technology: Energy-Friendly Compositions and Applications. US: Springer; 2010. p. 3-90

[12] Gonterman JR, Weinstein MA. Plasma melting technology and applications. In: Wallenberger FT, Bingham PA editors. Fiberglass and Glass Technology: Energy-Friendly Compositions and Applications. US: Springer; 2010. p. 431-451

[13] Hausrath RL, Longobardo AV. High-strength glass Fibers and markets. In: Wallenberger FT, Bingham PA editors. Fiberglass and Glass Technology: Energy-Friendly Compositions and Applications. US: Springer; 2010. p. 197-225

[14] Jones FR, Huff NT. Structure and Properties of Glass Fibres. In: A.R. Bunsell editor. Handbook of Tensile Properties of Textile and Technical Fibres. Cambridge: Woodhead Publishing; 2009. p. 529-573

[15] Sisecam, Turkey: Products [Internet]. 2017. Available from: http://www.sisecamkimyasallar.com/tr/faaliyet-alanlarimiz/cam-elyaf/sisecam-tek-uclu-fitil [Accessed: 2017-08-16]

[16] Fiberglass News: The Making of Glass Fiber [Internet]. 2017. Available from: https:// fiberglassnews.wordpress.com/tag/glass/ [Accessed: 2017-08-17]

[17] Jones JR. Glass fibres. In: Hearle JWS, editor. High-Performance Fibres. Cambridge: Woodhead Publishing Ltd.; 2001. pp. 197-238

[18] Wallenberger FT, Watson JC, Li H. Glass Fibers. ASM Handbook. 21: Composites. Ohio: American Technical Publishers Ltd; 2001. pp. 27-34

[19] High Strength Glass Fibers: AGY [Internet]. 2017. Available from: http://www.agy.com/ wp-content/uploads/2014/03/High_Strength_Glass_Fibers-Technical.pdf. [Accessed: 2017-06-05]

[20] Yolacan G. Experimentally determination of the mechanical properties of stitched and containing nano-particle multilayered E-glass/polyester woven fabric composites (thesis). Kayseri: Erciyes University; 2013 
[21] Mazumdar SK. Composites Manufacturing, Materials, Product and Process Engineering. Florida: CRC Press; 2002. pp. 46-154

[22] Offringa AR. Thermoplastic composites-rapid processing applications. Composites Part A: Applied Science and Manufacturing. 1996;27:329-336

[23] Iyer SR, Drzal LT. Manufacture of powder-impregnated thermoplastic composites. Journal of Thermoplastic Composite Materials. 1990;3:325-355

[24] Brandrup J, Immergut H, Grulke A. Polymer Handbook. 4th ed. New York: John Willey \& Sons, Inc.; 1999. p. 171

[25] Choi BD, Diestel O, Offermann P. Commingled CF/PEEK hybrid yarns for use in textile reinforced high performance rotors. In: 19th International Conference on Composite Materials (ICCM); 28 July-2 August 2013; Montreal; 2013. p. 1-10

[26] Loos M. Composites. In: Loos M, editor. Carbon Nanotube Reinforced Composites. Oxford: Elsevier; 2015. pp. 38-63

[27] Kickelbick G. Nanoparticles and composites. In: Levy D, Zayat M, editors. The Sol-Gel Handbook: Synthesis, Characterization and Applications. Weinheim: Wiley-VCH; 2015. pp. 227-244

[28] Chandradass J, Kumar MR, Velmurugan R. Effect of clay dispersion on mechanical, thermal and vibration properties of glass fiber-reinforced vinyl ester composites. Journal of Reinforced Plastics and Composites. 2008;27:1585-1601

[29] Friedrich K, Fakirov S, Zhang Z. Polymer Composites from Nano- to Macro-Scale. New York: Springer; 2005. pp. 3-23

[30] Gojny FH, Wichmann MHG, Fiedler B, Schulte K. Influence of different carbon nanotubes on the mechanical properties of epoxy matrix composites-A comparative study. Composites Science and Technology. 2005;65:2300-2313

[31] Thostenson ET, Li C, Chou TW. Nanocomposites in context. Composites Science and Technology. 2005;65:491-516

[32] Wetzel B, Haupeiit F, Friedrich K, Zhang MQ, Rong MZ. Impact and wear resistance of polymer nanocomposites at low filler content. Polymer Engineering and Science. 2002;42:1919-1927

[33] Wichmann MHG, Schulte K, Wagner HD. On nanocomposite toughness. Composites Science and Technology. 2008;68:329-331

[34] Grishchuk S, Schledjewski R. Mechanical dispersion methods for carbon nanotubes in aerospace composite matrix systems. In: Paipetis AS, Kostopoulos V, editors. Carbon Nanotube Enhanced Aerospace Composite Materials: A New Generation of Multifunctional Hybrid Structural Composites. New York: Springer; 2013. pp. 100-132

[35] Vilgis T, Heinrich G, Klüppel M. Reinforcement of Polymer Nano-Composites: Theory, Experiments and Applications. Cambridge: Cambridge University Press; 2009. pp. 75-100 
[36] Paipetis AS, Kostopoulos V. Carbon nanotubes for novel hybrid structural composites with enhanced damage tolerance and self-sensing/actuating abilities. In: Paipetis AS, Kostopoulos V, editors. Carbon Nanotube Enhanced Aerospace Composite Materials: A New Generation of Multifunctional Hybrid Structural Composites. New York: Springer; 2013. pp. $2-16$

[37] Vavouliotis AI, Kostopoulos V. On the use of electrical conductivity for the assessment of damage in carbon nanotubes enhanced aerospace composites. In: Paipetis AS, Kostopoulos V, editors. Carbon Nanotube Enhanced Aerospace Composite Materials: A New Generation of Multifunctional Hybrid Structural Composites. New York: Springer; 2013. pp. $22-52$

[38] Zhu J, Imam A, Crane R, Lozano K, Khabashesku VN, Barrera EV. Processing a glass fiber reinforced vinyl ester composite with nanotube enhancement of interlaminar shear strength. Composites Science and Technology. 2007;67:1509-1517

[39] Seyhan AT, Gojny FH, Tanoglu M, Schulte K. Critical aspects related to processing of carbon nanotube/unsaturated thermoset polyester nanocomposites. European Polymer Journal. 2007;43:374-379

[40] Yong V, Hahn HT. Processing and properties of SiC/vinyl ester nanocomposites. Nanotechnology. 2004;15:1338-1343

[41] Patnaik A, Satapathy A, Mahapatra SS, Dash RR. A comparative study on different ceramic fillers affecting mechanical properties of glass-polyester composites. Journal of Reinforced Plastics and Composites. 2009;28:1305-1318

[42] Dow NF. Triaxial fabric. US Patent 3446251, 27 May 1969

[43] Brunnschweiler D. Braids and braiding. Journal of the Textile Institute. 1953;44:666-686

[44] Lida S, Ohmori C, Ito T. Multiaxial fabric with triaxial and quartaxial portions. US Patent 5472020, 5 Dec 1995

[45] Hamada H, Ramakrishna S, Huang ZM. Knitted fabric composites, 3-D textile reinforcements in composite materials. In: Miravete A, editor. 3-D Textile Reinforcements in Composite Materials. Cambridge: Woodhead Publishing Ltd; 1999. pp. 180-216

[46] Padaki NV, Alagirusamy R, Sugun BS. Knitted preforms for composite applications. Journal of Industrial Textiles. 2006;35:295-321

[47] Technische Universitat Dresden [Internet]. 2017. Available from: http://tu-dresden.de/ die_tu_dresden/fakultaeten/fakultaet_maschinenwesen/itm/forschung/forschungsthemen/gl_gestrick [Accessed: 2017-05-29]

[48] Bilisik K, Karaduman NS, Bilisik NE. 3D fabrics for technical textile applications. In: Jeon HY, editor. Non-woven Fabrics. Intech; 2016. pp. 81-141

[49] Grafe T, Graham K. Polymeric nanofibers and nanofiber webs: A new class of nonwovens. International Nonwovens Journal. 2003;12:51-55 
[50] Anand SC. Technical fabric structures-knitted fabrics. In: Horrocks AR, Anand SC, editors. Handbook of Technical Textiles. 2nd ed. Cambridge: Woodhead Publishing Ltd.; 2016. pp. 107-162

[51] Advanced packaging Technologies [Internet]. 2017. Available from: http://advancepac. com/wordpress/markets/adhesive-specialty-films/glass-film/ [Accessed: 2017-08-05]

[52] Bilisik K, Yolacan G. Experimental characterization of multistitched two dimensional (2D) woven E-glass/polyester composites under low velocity impact load. Journal of Composite Materials. 2014;48:2145-2162

[53] Bilisik K, Yolacan G. Experimental determination of bending behavior of multilayered and multidirectionally-stitched E-glass fabric structures for composites. Textile Research Journal. 2012;82:1038-1049

[54] Bilisik K. Characterization of multi-stitched woven nano composites under compression after low velocity impact (CALVI) load. Polymer Composites. 2017:1-11. DOI: 10.1002/ pc.24406, (on line)

[55] Bilisik K. Multiaxis 3D woven preform and properties of multiaxis 3D woven and 3D orthogonal woven carbon/epoxy composites. Journal of Reinforced Plastics and Composites. 2010;29:1173-1186

[56] Bilisik K. Dimensional stability of multiaxis 3D woven carbon preform. Journal of the Textile Institute. 2010;101:380-388

[57] Bilisik K. Multiaxis three dimensional (3D) circular woven preforms-"radial crossing weaving" and "radial in-out weaving": Preliminary investigation of feasibility of weaving and methods. Journal of the Textile Institute. 2010;101:967-987

[58] Bilisik K. Three dimensional (3D) axial braided preforms: Experimental determination of effects of structure-process parameters on unit cell. Textile Research Journal. 2011; 81:2095-2116

[59] Bilisik K, Karaduman NS, Bilisik NE, Bilisik HE. Three dimensional (3D) fully interlaced woven preforms for composites. Textile Research Journal. 2013;83:2060-2084

[60] Mohamed MH, Bilisik K. Multilayered 3D fabric and method for producing. US Patent 5465760, 14 Nov 1995

[61] Bilisik AK. Multiaxial three dimensional (3D) circular woven fabric. US Patent 6129122, 10 Dec 2000

[62] Bilisik K, Karaduman NS, Bilisik NE. Fiber architectures for composite applications. In: Sohel R, Raul F. editors. Fibrous and Textile Materials for Composite Applications. US: Springer; 2016. p. 75-95

[63] Technical Design Guide for FRP Composite Products and Parts [Internet]. 2017. Available from: http://www.moldedfiberglass.com/sites/default/files/docs/MFG_Technical_ Design_Guide_FRP_Composite_0.pdf [Accessed: 2017-07-25] 
[64] Mouritz AP, Leong KH, Herszberg I. A review of the effect of stitching on the in-plane mechanical properties of fibre-reinforced polymer composites. Composites Part A: Applied Science and Manufacturing. 1997;28A:979-991

[65] Wu E, Wang J. Behavior of stitched laminates under in-plane tensile and transverse impact loading. Journal of Composite Materials. 1995;29:2254-2279

[66] Velmurugan R, Solaimurugan S. Improvements in mode I interlaminar fracture toughness and in-plane mechanical properties of stitched glass/polyester composites. Composites Science and Technology. 2007;67:61-69

[67] Aymerich F, Priolo P, Sun CT. Static and fatigue behaviour of stitched graphite/epoxy composite laminates. Composites Science and Technology. 2003;63:907-917

[68] Beier U, Fischer F, Sandler JKV, Altstadt V, Weimer C, Buchs W. Mechanical performance of carbon fibre-reinforced composites based on stitched preforms. Composites Part A: Applied Science and Manufacturing. 2007;38:1655-1663

[69] Wei Y, Zhang J. Characterization of microstructure in stitched unidirectional composite laminates. Composites Part A: Applied Science and Manufacturing. 2008;39:815-824

[70] Bilisik K, Yolacan G. Off-axis tensile properties of multistitched plain woven E-glass/ polyester composites. Fibers and Polymers. 2014;15:589-598

[71] Bilisik K, Yolacan G. Warp and weft directional tensile properties of multistitched biaxial woven E-glass/polyester composites. Journal of the Textile Institute. 2014;105:1014-1028

[72] Bilisik K, Yolacan G. Warp-weft directional bending properties of multistitched biaxial woven E-glass/polyester nano composites. Journal of Industrial Textiles. 2015;45:66-100

[73] Bilisik K, Yolacan G. Short beam strength properties of multistitched biaxial woven E-glass/polyester nano composites. Journal of Industrial Textiles. 2015;45:199-221

[74] Zhao N, Rodel H, Herzberg C, Gao SL, Krzywinsky S. Stitched glass/PP composite. Part I: Tensile and impact properties. Composites Part A: Applied Science and Manufacturing. 2009;40:635-643

[75] Farley GL. A mechanism responsible for reducing compression strength of throughthe-thickness reinforced composite material. Journal of Composite Materials. 1992; 26:1784-1795

[76] Lee C, Liu D. Tensile strength of stitching joint in woven glass fabrics. Journal of Engineering Materials and Technology. 1990;112:125-130

[77] Tan KT, Watanabe N, Iwahori Y. Impact damage resistance, response, and mechanisms of laminated composites reinforced by through-thickness stitching. International Journal of Damage Mechanics. 2012;21:51-80

[78] Tan KT, Watanabe N, Iwahori Y. X-ray radiography and micro-computed tomography examination of damage characteristics in stitched composites subjected to impact loading. Composites Part B: Engineering. 2012;42:874-884 
[79] Chen G, Li Z, Kou C, Gui L. Finite element analysis of low-velocity impact damage of stitched laminates. Journal of Reinforced Plastics and Composites. 2004;23:987-995

[80] Xiaoquan C, Al-Mansour AM, Zhengneng L, Chenghe K. Compression strength of stitched laminates after low-velocity impact. Journal of Reinforced Plastics and Composites. 2005;24:935-947

[81] Truong TC, Vettori M, Lomov S, Verpoest I. Carbon composites based on multi-axial multi-ply stitched preforms. Part 4. Mechanical properties of composites and damage observation. Composites Part A: Applied Science and Manufacturing. 2005;36:1207-1221

[82] Bilisik K, Yolacan G. Low-velocity impact characterization of multistitched woven E-glass/polyester nano/micro composites. Textile Research Journal. 2014;84:1411-1427

[83] Use of Composite Materials in Aerospace [Internet]. 2017. Available from: https://compositesuk.co.uk/composite-materials/applications/aerospace [Accessed: 2017-07-03]

[84] Composites in the Airframe and Primary Structure. 2017. Available from: http://www. boeing.com/commercial/aeromagazine/articles/qtr_4_06/article_04_2.html [Accessed: 2017-08-17]

[85] Uses of Fiberglass [Internet]. 2017. Available from: https://www.thoughtco.com/uses-offiberglass-820412 [Accessed: 2017-07-05]

[86] Automotive Glass Fiber Composites Market-Growth Trends and Forecasts (2015-2020) [Internet]. 2015. Available from: https://www.mordorintelligence.com/industry-reports/ automotive-glass-fiber-composites-market [Accessed: 2017-08-20]

[87] Composites: On good form [Internet]. 2014. Available from: https://automotivemanufacturingsolutions.com/process-materials/on-good-form composite-materials [Accessed: 2017-08-21]

[88] Market reports [Internet]. 2017. Available from: http://www.lucintel.com/lucintelbrief/lucintel-brief-opportunity-and-challenges-in automotive-composites-industry.pdf [Accessed: 2017-08-21]

[89] Technical Report of Ship Structure Committee, SSC-360. Use of Fiber Reinforced Plastics in the Marine Industry. September 1990

[90] Printed Circuit Boards: A Mobile Market [Internet]. 2017. Available from: http://www.compositesworld.com/articles/printed-circuit-boards-a-mobile-market [Accessed: 2017-08-21]

[91] Paulson JA, Mesbah A, Zhu X, Molaro MC, Braatz RD. Control of self-assembly in micro and nano-scale systems. Journal of Process Control. 2015;27:38-49

[92] Fiberglass News [Internet]. 2017. Available from: https://fiberglassnews.wordpress.com/ tag/glass/ [Accessed: 2017-08-16]

[93] Glass Armor Systems: AGY [Internet]. 2017. Available from: http://www.agy.com/wp-content/uploads/2014/03/S-2_Glass_Armor_Systems-Defense.pdf [Accessed: 2017-08-22] 
[94] Bhatnagar A. Lightweight Ballistic Composites: Military and Law-Enforcement Applications. Florida: CRC Press; 2006. pp. 400-408

[95] Wallenberger FT. Energy-friendly compositions and applications. In: Wallenberger FT, Bingham PA, editors. Fiberglass and Glass Technology. New York: Springer Science+ Business Media; 2010

[96] Kadir Bilisik, Nesrin Karaduman, Nedim Erman Bilisik, Fiber architectures for composite applications. In: Raul Fangueiro, Sohel Rana, editors. Fibrous and Textile Materials for Composite Applications. Singapore: Springer Science+Business Media; 2016. pp. 75-134

[97] Bilisik K. Impact resistant fabrics. In: Miao M, Xin J, editors. Engineering of High Performance Textiles. New York: Elsevier Limited-Woodhead Publishing; 2017 